\title{
A PEDOLOGIA NOS CURSOS DE GEOGRAFIA DA UNESP: O TEMA SOLOS E SUA ATUAÇÃO NA EDUCAÇÃO AMBIENTAL
}

\author{
Estevão Conceição Gomes Junior ${ }^{1}$ \\ Maria Cristina Perusi ${ }^{2}$ \\ Débora Jurado Ramos ${ }^{3}$
}

\begin{abstract}
Resumo
Oferecido nos campi de Ourinhos, Presidente Prudente e Rio Claro, o curso de Geografia da Universidade Estadual Paulista "Júlio de Mesquita Filho" (Unesp) pode ser encontrado nas modalidades licenciatura e bacharelado, nos períodos diurno, noturno e integral, com turmas entre 40 e 45 alunos. O geógrafo possui a missão de compreender os elementos e o processo de produção do espaço geográfico, seja ele urbano ou rural, sob uma perspectiva integrada dos aspectos econômicos, políticos, sociais, culturais, ambientais etc. Nessa direção, a educação em solos, uma das vertentes da educação ambiental, pode ser entendida como tema integrador, por ser resultado dos processos e fatores naturais. Além disso, o recurso solo, já não tão natural, é primordial para o desenvolvimento de macro e microrganismos, dentre eles, os que alimentam a maioria da população humana, o que por si só justificaria sua importância. A disseminação das práticas de uso e conservação dos solos se mostra como uma tarefa relevante para os futuros professores e bacharéis em Geografia, principalmente àqueles voltados para as discussões acerca da problemática ambiental. Portanto, objetiva-se analisar a estrutura curricular do curso de Geografia dos três câmpus da Unesp, no que diz respeito à disciplina de Pedologia, e as possibilidades de estudos voltados para a educação ambiental. Observou-se uma baixa conformidade entre a oferta da disciplina nas unidades estudadas e o desenvolvimento de pesquisas direcionadas à educação em solos e/ou problemáticas ambientais, exemplificado pelo baixo número de trabalhos de conclusão de curso gerados pelos alunos egressos, o que, consequentemente, pôde ter limitado os estudos e discussão acerca da educação ambiental e/ou educação em solos.
\end{abstract}

Palavras-chave: Educação ambiental. Ciência do solo. Educação em solos. Licenciatura e bacharelado em Geografia. Pedologia.

\section{PEDOLOGY IN THE GRADUATION COURSES OF GEOGRAPHY FROM UNESP: SOILS AND THEIR ROLE IN ENVIRONMENTAL EDUCATION}

\footnotetext{
Abstract

Offered in the Ourinhos, Presidente Prudente and Rio Claro faculties, the graduation course of Geography from the Universidade Estadual Paulista "Júlio de Mesquita Filho" (UNESP) can be found in the licentiate and bachelor degrees, in the morning, integral (Campus Rio Claro) and nighttime periods, with classes having between 40 and 45 students. The geographer has the mission of understanding the elements and the production process of both urban or rural geographical spaces, under an integrated perspective of economic, political, social, cultural, environmental aspects. Thus, soil education, one of the aspects of environmental education,

${ }^{1}$ Doutorando em Geografia. Centro de Ciências Exatas - Universidade Estadual de Londrina (UEL), Londrina, Paraná, Brasil.

2 Professora Assistente da Universidade Estadual Paulista “Júlio de Mesquita Filho" - Campus de Ourinhos. Ourinhos, São Paulo, Brasil.

${ }^{3}$ Mestranda em Geografia - Centro de Ciências Exatas - Universidade Estadual de Londrina (UEL), Londrina, Paraná, Brasil.
} 
can be understood as an integrating theme, as it results from natural processes and factors. In addition, the soil resource, not so natural nowadays, is essential for the development of macro and microorganisms, among them, those feeding most of the human population, which in itself justifies its importance. The dissemination of land use and conservation practices is a relevant task for future teachers and bachelors in Geography, especially those focused on discussions about environmental issues. Therefore, this study aims to analyze the curricular structure of the Geography course from the three UNESP campuses, regarding Pedology discipline, and the possibilities of studies focused on environmental education. A low conformity between the offer of the discipline in the studied campuses and the development of studies on education in environmental soils and/or problems was observed, which could be exemplified by the low number of final works by the graduates, which, consequently, may have limited the studies and discussion about environmental education and/or soil education.

Keywords: Environmental education. Soil science. Soil education. Bachelor's degrees. Pedology.

\section{LA PEDOLOGÍA EN EL CURSO DE GEOGRAFÍA DE UNESP: EL TEMA SUELOS Y SU ACCIÓN EN LA EDUCACIÓN AMBIENTAL}

\section{Resumen}

La Universidad Estadual Paulista "Júlio de Mesquita Filho" (UNESP) oferta el curso de Geografía en las modalidades profesorado y licenciatura, en los periodos diurno, integral y nocturno, en los campi Ourinhos, Presidente Prudente y Río Claro, con grupos entre 40 y 45 alumnos. El geógrafo tiene la misión de comprender los elementos y el proceso de producción del espacio geográfico, ya sea urbano o rural, desde una perspectiva integrativa de los aspectos económicos, políticos, sociales, culturales, ambientales, etc. En este sentido, la educación en suelos, una de las vertientes de la educación ambiental, puede entenderse como tema integrador, por ser resultado de los procesos y factores naturales. Además, aunque no tan natural, el recurso suelo es primordial al desarrollo de macro y microorganismos, entre ellos los que alimentan a la mayoría de la población humana, lo que por sí solo justificaría su importancia. La diseminación de las prácticas de uso y la conservación de los suelos se muestra como una tarea relevante a los futuros profesores y licenciados en Geografía, principalmente a quienes se dedican a discutir sobre la problemática ambiental. Por lo tanto, se pretende analizar el plan curricular del curso de Geografía de los tres campi de la UNESP, en lo que se refiere a la disciplina de Pedología, y las posibilidades de estudios dirigidos a la educación ambiental. Se observó una baja conformidad entre la oferta de la disciplina en los campi estudiados y el desarrollo de investigaciones sobre la educación en suelos y/o problemáticas ambientales, lo se ejemplifica por el bajo número de trabajos de conclusión de curso de los alumnos egresados, que, por consiguiente, pudo haber limitado los estudios y la discusión sobre la educación ambiental y/o la educación en suelos.

Palabras clave: Educación ambiental. Ciencia del suelo. Educación del suelo. Profesorado y Licenciatura en Geografía. Pedología.

\section{Introdução}

Com pouco mais de um século de existência, a Pedologia, também conhecida como ciência do solo, foi sistematizada inicialmente pelo naturalista e geógrafo V. Dokuchaev, ao perceber o solo como resultado da complexa interação entre diferentes elementos da natureza; no Brasil, por decreto do imperador D. Pedro II, foi criada, em 1887 a Estação Agronômica de 
Campinas, que mais tarde passou a ser o Instituto Agronômico de Campinas (IAC) (MONIZ, 1997).

Além do conceito tradicional de solo desenvolvido por Jenny (1941), outras definições foram amplamente difundidas, tendo em vista a problemática ambiental e a influência antrópica na alteração do solo. Segundo a obra Soil Taxonomy (USDA, 1999), "solo é a coletividade de indivíduos naturais, na superfície da Terra, eventualmente modificado ou mesmo construídos pelo homem, contendo matéria orgânica viva e servindo ou sendo capaz de servir a sustentação de plantas ao ar livre'.

Com o incremento de novas características, a conceituação de solo publicada por importantes órgãos ao redor do mundo, como o Departamento de Agricultura dos Estados Unidos (Usda), Comitê Australiano do Solo e Superfície Terrestre (NCST) e a Empresa Brasileira de Pesquisa Agropecuária (Embrapa) fez com que estudos - , discutidos por geógrafos, biólogos, engenheiros ambientais, e tantos outros profissionais - abordassem o recurso natural solo e sua relevância para a vida humana.

Devido à evidência dos impactos negativos sobre os ecossistemas de maneira geral e, em especial no sistema solo, a Organização das Nações Unidas (ONU) declarou o ano de 2015 como o Ano Internacional do Solo; e como foi apresentado na $68^{\circ}$ Sessão da Assembleia Geral da ONU, o dia 5 de dezembro de 2015 marcou o Dia Mundial do Solo. Algumas das diretrizes estipuladas na Assembleia foram discutidas ao longo de 2015 em fóruns, simpósios e congressos liderados pela International Union of Soil Science (IUSS), tendo como destaque:

1. A elevação do recurso solo como base para o desenvolvimento agrícola e essencial para a manutenção adequada dos ecossistemas, e ainda um recurso vital para a segurança alimentar, culminando então para preservação da vida na Terra.

2. O reconhecimento da sustentabilidade dos solos como fundamental para enfrentar as dificuldades de uma população crescente, buscando o estudo, defesa e apoio para a promoção de gestões sustentáveis do solo e, portanto, ações que busquem a segurança alimentar do mundo e ecossistemas sustentáveis.

As diretrizes acima citadas foram utilizadas para basear o $21^{\circ}$ Congresso Mundial de Ciência do Solo que ocorrerá em agosto de 2018 no Brasil sob o título Solos como semente e combustível do mundo. Tem-se então que popularizar a educação em solos, que busca não apenas conscientizar as pessoas da importância do solo na vida dos seres, mas que esse recurso pode ser inserido em processos educativos para melhoria da realidade ambiental. A educação em solos tem como objetivo geral criar, desenvolver e consolidar a sensibilização de todos em relação ao solo e promover o interesse para sua conservação, uso e ocupação sustentáveis (MUGGLER; SOBRINHO; MACHADO, 2006).

A Pedologia, em suas diferentes frentes de abordagem, se configura como uma ciência integradora na problemática ambiental. Isso ocorre porque o solo é um dos elementos da natureza de maior complexidade no funcionamento do ambiente (RUELLAN; DOSSO, 1993; CUNHA et al., 2013).

Assim a Pedologia, no curso de Geografia da Universidade Estadual Paulista “'Júlio de Mesquita Filho", não é visto pela totalidade de seus alunos, o que pode configurar um problema estrutural na formação do geógrafo. É justamente nessa disciplina que discussões como gênese, distribuição espacial e fertilidade do solo são discutidas, de importância significativa nas mais variadas áreas da Geografia, como Geografia Urbana, Geografia Agrária, Ensino de Geografia, entre outros.

Dessa forma, o objetivo da pesquisa é evidenciar a estruturação da disciplina de Pedologia nos cursos de Geografia da Unesp e seu reflexo na formação dos recém-licenciados e bacharéis em Geografia. 
Para atingir tal objetivo, fez-se uma discussão acerca do desenvolvimento da Geografia no ensino escolar (anos iniciais) e superior, baseando-se fundamentalmente nas perspectivas epistemológicas filosóficas de Chervel (1990) e Goodson (1990).

Visando compreender a formulação da disciplina de Pedologia nos cursos de Geografia na Unesp e as possibilidades de estudos voltados para a educação ambiental, foram analisadas as ementas da disciplina em nível de graduação nos três campi onde é oferecida (Ourinhos, Presidente Prudente e Rio Claro), além de entrevistas e aplicação de questionários para alunos egressos.

\section{A construção da geografia no ensino superior brasileiro}

Como sugerido por Rocha (1996), a década de 1930 é marcada pelo surgimento dos primeiros cursos de formação de professores de Geografia. Por meio do Decreto 19.851 de 11 de abril de 1931, o então ministro Francisco Campos renovava o ensino superior brasileiro com a introdução do sistema universitário.

$\mathrm{O}$ debate direcionado à formação de professores pôde aprofundar o estudo sobre a funcionalidade, aplicabilidade e desafios dos novos professores no mercado de trabalho, uma vez que, direta ou indiretamente, atribui-se à educação a solução para os grandes embates sociais. Pacheco (2003) indica que a institucionalização da formação de professores em meados dos anos de 1091 com as instituições religiosas como ordens docentes, até os dias de hoje, tem seguido de forma consistente o caminho da universalização, na medida em que se tornou incontornável a formação no seio das instituições de ensino superior.

Procurando discutir a relação entre a formação de professores e a disciplina de Geografia, Castelar (2003) pondera a atitude do licenciado com relação ao conhecimento e sua aplicabilidade para com os alunos. Para a autora "o professor deve aturar no sentido de se apropriar de sua experiência, do conhecimento que tem para investir em sua emancipação e em seu desenvolvimento profissional, atuando efetivamente no desenvolvimento curricular e deixando de ser mero consumidor"' (p. 52-53, grifo nosso). O termo consumidor se refere aos professores que se especializam, mas não partilham os produtos do estudo com os educandos, ou seja, não executa o ato de ensinar.

Sendo assim, Castelar sinaliza que o sistema educacional deve unir simultaneamente à formação inicial e continuada de professores, condições de trabalhos dignas, relação trabalhosalário firmada etc. Ela é enfática em interpretar que a tarefa docente consiste em organizar, programar e dar sequência aos conteúdos, de forma que o aluno possa realizar uma aprendizagem significativa, encaixando novos conhecimentos em sua estrutura cognitiva, evitando em suma a memorização - característica empregada ao modelo de ensino de Geografia no início do século XX.

Souza Junior e Galvão (2005) propõem a discussão das disciplinas escolares e sua direta ligação com as matérias praticadas na universidade. Para isso, ressalta dois pensadores da epistemologia educacional: Chervel (1990) com o estudo das disciplinas escolares na França e Goodson (1990) com o estudo das disciplinas escolares o Reino Unido. Em suma, Chervel relata que o não estudo das disciplinas elaboradas nos currículos elimina o caráter criativo do ensino e ignora o papel que a instituição desempenha na sociedade. Ele menciona ainda que:

Pode-se globalmente supor que a sociedade, a família, a religião experimentam, em determinada época histórica, a necessidade de delegar certas tarefas educacionais a uma instituição especializada, e que as grandes finalidades educacionais que emanam da sociedade global não deixaram de evoluir com as épocas e os séculos, e que os comanditários sociais das instituições conduzem permanentemente os principais objetivos da instrução e da educação aos quais ela se encontra submetida (CHERVEL, 1990, p. 181). 
Chervel intensificou seus estudos na epistemologia das disciplinas escolares dos anos primários e ginasiais - atual ensino fundamental no Brasil, enfatizando que o conhecimento dos planos de estudos, manuais ou qualquer outro material que explicite os conteúdos a serem desenvolvidos em uma disciplina é de suma importância para sua própria alteração ou complementação.

Goodson (1990) parte de um princípio filosófico para fundamentar seu estudo acerca das disciplinas escolares no Reino Unido. Um conceito-chave utilizado pelo autor para discorrer sobre a epistemologia das disciplinas é o de visão oficial. Santos (2005) dota a esse conceito a ideia de que as disciplinas escolares teriam nascido de uma disciplina acadêmica, sendo assim, estudiosos da universidade teriam elaborado uma disciplina adaptada para o ambiente escolar primário, ginasial e colegial. Já Goodson (1990) sinaliza que os contextos escolar e universitário são distintos e não há associação em nenhuma escala de suas disciplinas. Para o autor, a consolidação das disciplinas escolares é antecedida das disciplinas acadêmicas, uma vez que essa ciência se desenvolveu a priori nas escolas elementares e secundárias na Inglaterra e por uma propulsão social veio a se tornar uma ciência acadêmica com ênfase para o magistério anos depois.

Para Santos (2005), a geografia brasileira se enquadra na perspectiva de Goodson, uma vez que a Geografia enquanto curso superior teve sua origem nos anos de 1930 e a matéria Geografia, no ensino primário, surgiu na segunda metade dos anos de 1880 . Vale ressaltar que a primeira instituição de ensino superior a abrigar o curso de Geografia foi a Faculdade de Filosofia, Letras e Ciências Humanas da Universidade de São Paulo (USP) no ano de 1934.

Sob olhar específico para o ensino superior, Pereira (1989) comenta que a participação dos geógrafos estrangeiros foi de suma importância para direcionar e auxiliar os primeiros profissionais formados em Geografia no Brasil, debatendo métodos de pesquisa, técnicas de análise de dados, ou seja, sistematizando a direção que a Geografia acadêmica brasileira poderia seguir. $\mathrm{O}$ autor menciona ainda que nesse período surgiram muitos trabalhos importantes de geografia regional, criando um material tipicamente brasileiro, tratando-se da primeira vez no país que os estudos geográficos e as pesquisas realizadas tiveram a orientação de geógrafos propriamente ditos.

Com esse cenário, era nítido que a Geografia era lecionada por intelectuais da época e a eficácia da discussão dependeria em grande parte do profissional que ali estaria ensinando, muitas vezes bacharéis em Direito, onde era obrigatório cursar a disciplina de Geografia no ensino secundário/complementar.

A formação dos licenciados em Geografia teve absoluta mudança no currículo brasileiro, dando a esses profissionais uma concepção acadêmica e de exercício efetivo da profissão enquanto professores de sua disciplina de estudo. Rocha (1996) comenta que a formação desses licenciados é significativa para a propagação da orientação moderna da geografia escolar e que com a criação de cursos de Geografia no ensino superior inauguraram a fase moderna da matéria no país.

Portanto, o curso oferecido nos campi de Ourinhos, Presidente Prudente e Rio Claro se encontram na fase moderna da Geografia no Brasil, e apresentam particularidades na pesquisa, ensino, extensão universitária e estrutura curricular.

\section{A Pedologia na Geografia e sua aplicabilidade na educação ambiental}

Diante das bases e conceitos discutidos costumeiramente pelos geógrafos, a citar a interação entre os agentes naturais e antrópicos, a Pedologia se apresenta como objeto de estudo significativo, seja pelas condições naturais da formação do solo ou pela forma como o homem contribui (positivamente e negativamente) para a consolidação dos depósitos tecnogênicos e Antropossolos. 
Ainda que a Pedologia seja muito recorrente em diversas pesquisas nas Ciências Naturais, foi na Geografia que obteve grande importância. Não apenas pelo fato de seu grande expoente e sistematizador ser um geógrafo russo, mas pela transversalidade observável na relação integradora entre homem e natureza.

Nessa perspectiva, Queiroz Neto (1986) sugere a inter-relação indissociável do solo com outros elementos da paisagem, sendo o objeto de estudo da Pedologia o conhecimento dos processos, mecanismos e resultados do solo em sua mais ampla dimensão. Trata-se então da análise integrada dos elementos naturais como os fatores de formação dos solos proposta por Jenny (1941) na abordagem tradicional. Já em novas abordagens, a equação Scorpan (McBratney et al., 2003) possibilita o reconhecimento da localização espacial como resultado da dinamicidade das ações naturais e antrópicas no solo.

A educação em solos, linha de pesquisa reconhecida pela Sociedade Brasileira de Ciência do Solo, se apresenta como campo produtivo para estudos ligados à questão ambiental. No entanto, o espaço dedicado ao estudo do solo é frequentemente nulo ou relegado a um plano menor nos conteúdos de ensino nas escolas, o que contribui para o desconhecimento da população às questões pedológicas (SILVA; RIBEIRO, 2004, p. 145).

A apropriação dos conteúdos básicos da Pedologia pelos futuros licenciados e bacharéis em Geografia é o primeiro passo para a fortificação da abordagem da equação Scorpan dentro de sala de aula e nos mais diversos ambientes de atuação profissional. O ensino dessa ciência permite a criação de consciência ambiental, tendo em vista o solo enquanto componente natural e antrópico, que está presente no cotidiano de todos, ou seja, é algo inerente à vida humana e possui uma importância socioeconômica vital para o funcionamento da sociedade.

Como aplicabilidade do tema solos na educação ambiental, Ramos et al. (2017) indicam uma forte tendência de utilização nos estudos direcionados a urbanização, aumento populacional, reciclagem, conservação dos aquíferos e degradação dos recursos naturais.

Segundo Santos e Benevides (2015), há certa deficiência no sistema de abordagem do solo nas escolas; e nesse sentido, Biondi e Falkowski (2009) verificaram que a utilização do tema solos visando a educação ambiental apresenta aceitação significativa na educação formal e não formal, por meio da aplicação de mapas mentais e testes estatísticos não paramétricos, como o teste de Wilcoxon, com destaque para conteúdos como variação dos horizontes pedogenéticos, impacto do relevo na formação do solo e influência da vegetação no regime térmico do solo.

Assim, observa-se um vasto horizonte de possibilidades de estudos que integram o tema solos com questão ambiental, a citar a urbanização discutida pela geografia urbana, a precipitação pluviométrica e infiltração discutidas pela hidrologia ou ainda a relação pedogênese x morfogênese estudada na Geomorfologia. Portanto, a apropriação dos conceitos básicos em ciência do solo pelos futuros licenciados e bacharéis em Geografia tendem a consolidar a ideia de "consciência pedoambiental", constituída pela adoção das premissas da Pedologia no ensino em nível infantil, fundamental, médio e superior nas mais variadas áreas do conhecimento, visando o reconhecimento e manutenção dos solos e de seus atributos.

\section{Resultados e discussão}

\subsection{Análise da estrutura curricular do curso de Graduação em Geografia na Unesp}

Em meio a grandes discussões da compreensão do espaço vivido, fundamentos filosóficos e interpretação da paisagem, a Geografia enquanto ciência construiu sua base como 
carreira acadêmica na busca por formar um profissional que analise o espaço e suas dinâmicas naturais e humanas. Para Costa (2012), no Brasil, os caminhos da Geografia como disciplina acadêmica e também escolar foram traçados sob influência das ideias da escola alemã, trazida pelos franceses, mas acrescidas pelas críticas da escola de Geografia criada por Paul Vidal de La Blache (1845-1918).

O projeto político pedagógico do curso de Geografia da Faculdade de Ciências e Tecnologia (FCT) da Unesp, em seu terceiro capítulo, discute a estrutura curricular proposta para o campus de Presidente Prudente. No subcapítulo 3.5 discorre-se sobre a base comum dos cursos de graduação em Geografia de Presidente Prudente e Rio Claro, onde:

De acordo com a Resolução UNESP nº 03/01: Cursos iguais da UNESP deverão ter uma base comum, estruturada a partir de núcleos básicos ou integradores de modo a garantir certa semelhança entre os currículos, mas permitindo uma diversificação consoante com a história e filosofia de cada curso, com vistas a garantir um padrão mínimo de currículo para os cursos de graduação da UNESP (FCT-UNESP, 2004, p.14).

A estrutura curricular do curso de Geografia do campus de Ourinhos passou por uma reformulação em 2012 para entrar em vigor já para a 12 turma de ingressantes; e em 2016 houve uma nova mudança curricular.

De acordo com o Regimento Geral da Unesp atualizado em 27/11/2012, em seu Título IV - Do ensino, da Pesquisa e da Extensão de Serviços à comunidade - o Artigo 63 trata sobre os cursos de graduação oferecidos pela universidade. No inciso I, cita-se que "as disciplinas serão programas homogêneos e completos em si mesmos, com base nos quais se organizarão os currículos dos diversos cursos" e que "na elaboração dos planos de ensino das disciplinas devem ser obedecidas diretrizes básicas, como definição dos objetivos, metodologia de ensino e conteúdo programático". Nesse contexto, observou-se que a disciplina de Pedologia ofertada nos três campi não segue uma base comum de oferta, como observado no quadro 1:

Quadro 1 - Oferta da disciplina de Pedologia no curso de Geografia da Unesp

\section{OFERTA DA DISCIPLINA DE PEDOLOGIA NO CURSO DE GEOGRAFIA DA} UNESP

\begin{tabular}{c|c|c|c}
\hline Campi & $\begin{array}{c}\text { Obrigatória para } \\
\text { Licenciatura }\end{array}$ & $\begin{array}{c}\text { Obrigatória para } \\
\text { Bacharelado }\end{array}$ & Optativa \\
\hline Ourinhos & Sim & Sim & Não \\
\hline Presidente Prudente & Não & Não & Sim \\
\hline Rio Claro & Sim & Sim* & Não* \\
\hline
\end{tabular}

*Em Rio Claro a disciplina de Pedologia é obrigatória para o Bacharelado sem ênfase, com ênfase em Análise Ambiental e Geoprocessamento e com ênfase em Análise Sócio Espacial e Planejamento Territorial.

Fonte: FCT-UNESP (2014), IGCE (2014) e Campus de Ourinhos (2015).

\subsection{A disciplina de Pedologia no campus de Presidente Prudente}

Oferecida na Faculdade de Ciências e Tecnologia, a Pedologia não compõe, desde 2016, o rol de disciplinas ofertadas para licenciatura e bacharelado. Sua ementa do ano de 2014 estava disposta na seguinte sequência programática:

1. A Pedologia e sua relação com a Geografia;

2. Gênese de solo;

3. Características morfológicas do solo; 
4. Classificação dos solos do Oeste Paulista;

5. Controle da Erosão e Manejo de solos.

A disciplina de Pedologia tem como seriação ideal proposta pelo programa de ensino o $1^{\circ}$ semestre do $3^{\circ}$ ano, sendo uma disciplina optativa como já mencionado, com quatro créditos, com carga horária dividida entre horas teóricas e práticas. Nesse campus, há um limite de alunos para cursar essa disciplina nos períodos noturno e diurno, sendo ele de cinquenta alunos em cada turno. A disciplina propunha como objetivos a expertise do aluno em identificar as principais classes de solo no campo e avaliar suas características morfológicas e físicas.

Com base nos programas de ensino da graduação para a disciplina de Pedologia, observou-se que entre 2004 e 2014 foi trabalhada no início das aulas a relação direta entre a ciência pedológica e a Geografia, inserindo o agente antrópico como modelador da paisagem. Esse tópico inicial teve como bibliografia básica no ano de 2014 o livro Geografia do Solo (1971) do naturalista B. T. Bunting, que propõe um estudo detalhado dos fatores de formação do solo, microfauna e microflora e uma descrição da localização dos solos na Terra.

Entre os anos de 2012 e 2014, o segundo tópico abordado na disciplina foi os processos de formação e composição do solo, onde se discutiram no último ano que a disciplina foi oferecida (2014) os cinco fatores de formação do solo (material de origem, clima, relevo, organismos, homem e tempo).

Em todos os planos de ensino analisados observou-se a menção ao estudo das propriedades físicas do solo, como textura, estrutura, consistência, permeabilidade etc. Nesse sentido, com esses estudos, o licenciado em Geografia seria capaz de realizar contato com seus alunos da educação básica acerca das percepções pedológicas condicionadas ao tato humano; a propriedade textura poderia indicar aos alunos, em um exemplo hipotético, a presença ou não da fração de areia no quintal de sua casa ou no jardim da escola, ressaltando que o solo apresenta partículas dos mais variados tamanhos e que essa condicionante reflete diretamente na quantidade de água que penetra o solo e nutre a vegetação.

Com relação ao estudo das classes de solo, observou-se a predominância das aulas voltadas às classes de maior representatividade no território brasileiro (Latossolos, Argissolos Neossolos e Gleissolos), com a proposta de mapeamento das classes no estado de São Paulo, bem como sua relação com a indústria agropecuária e agrícola.

\subsection{A disciplina de Pedologia no campus de Rio Claro}

É ofertada no Instituto de Geociências e Ciências Exatas (IGCE) como obrigatória para a formação em licenciatura e bacharelado com ênfase em Análise Ambiental e Geoprocessamento ou com ênfase em Planejamento Territorial e Geoprocessamento.

A ementa da disciplina dos anos de 2015 e 2016 está disposta na seguinte sequência programática:

1. Solo, um meio organizado;

2. Gênese, evolução dos solos, química e mineralogia dos solos;

3. Análise da estrutura da cobertura dos solos;

4. Modalidade de distribuição lateral dos horizontes pedológicos e cartografia dos solos;

5. Classificação brasileira de solos: os principais grandes grupos.

A disciplina de Pedologia tem como seriação ideal proposta pelo programa de ensino o $1^{\circ}$ semestre do $3^{\circ}$ ano, a exemplo do programa elaborado pela FCT, sendo uma disciplina obrigatória nos casos citados, com quatro créditos, com carga horária dividida entre horas teóricas (25h), práticas (20h), teórico-práticas (8h) e outras (7h). Nesse Campus não há limite 
de alunos para cursar essa disciplina nos períodos noturno e integral indicados no programa de ensino.

Com base no programa de ensino de Pedologia em Rio Claro, observou-se que em 2016 foi trabalhada, no início das aulas, a conceituação de categorias-chaves da Geografia, como solo e Pedologia. Esse tópico inicial abordou o desenvolvimento da ciência pedológica no que diz respeito à ótica verticalista e tridimensional dos solos. No segundo tópico do conteúdo programático, propõe-se um estudo detalhado da formação e evolução dos solos, além de noções básicas em mineralogia e química dos solos.

Seguindo, tem-se o estudo dos níveis de organização da estrutura de um solo, levando em consideração a observação e a descrição dos volumes verificados. Aspectos morfológicos, como cor, textura e estrutura também são estudados nesse tópico.

No presente plano de ensino há uma menção significativa para o estudo da distribuição dos solos e o emprego da Cartografia como ferramenta de interpretação. No tópico referente ao mapeamento de solos, citam-se as categorias de observação: exploração, semidetalhe e detalhe, além da análise bidimensional em litossequência, topossequência, cronossequência e biossequência.

\subsection{A disciplina de Pedologia no campus de Ourinhos}

É ofertada no $2^{\circ}$ semestre do $1^{\circ}$ ano, sendo obrigatória para as modalidades de licenciatura e bacharelado. A ementa proposta para o ano de 2017 mostra a seguinte conformidade:

1. Introdução à Pedologia;

2. Conceitos de solo e fatores de formação;

3. Intemperismo e formação do solo;

4. Composição do solo;

5. Perfil de solo, camadas e horizontes diagnósticos de superfície e subsuperfície;

6. Classificação dos solos;

7. Degradação/conservação do solo;

8. Uso e ocupação dos solos;

9. Fotopedologia.

As aulas teóricas (32h), práticas (12h) e prática pedagógica (16h) compõem a carga horária total de $60 \mathrm{~h}$. Nas teóricas, são abordados conceitualmente os conteúdos propostos. A prática inclui trabalhos de campo, visando a práxis geográfica. A prática pedagógica engloba a amostragem de solo nas cidades de origem dos alunos, criando um "espaço de diálogo", em que as principais características morfológicas são descritas em conjunto, além da elaboração de materiais didáticos.

A inserção das práticas pedológicas pode influenciar diretamente na formação de cidadãos mais ativos na busca pela conservação desse recurso cada vez mais exaurido. Para Oliveira e Cunha (2012), as décadas de 1960 e 1970 despontam como um marco de emergência sobre questionamentos e manifestações ecológicas, em nível mundial, além ainda da problemática da degradação dos elementos da natureza inflar a cada ano no seio da sociedade, interferindo diretamente na qualidade de vida, uma vez que a educação ambiental é um instrumento pertinente de difusão, de gestão, por sua capacidade de intervir no processo de construção social.

Portanto, há pouca semelhança entre os planos de ensino de Ourinhos, Presidente Prudente e Rio Claro, seja pela oferta da disciplina, conteúdo programático ou referencial bibliográfico disposto nas ementas. 


\subsection{Alunos egressos de Geografia da Unesp}

A fim de verificar a abrangência da disciplina de Pedologia na formação inicial de professores no curso de Geografia nos três campi da Unesp, foram elaborados e aplicados questionários. Ao todo, foram contabilizados 240 participantes (alunos egressos), que responderam perguntas sobre a oferta da disciplina de Pedologia, a utilização de suas bases e conceitos no mercado de trabalho e a elaboração/participação de iniciações científicas e/ou trabalhos de conclusão de curso em temas propondo discussões sobre a educação ambiental.

Foram realizadas as seguintes perguntas:

1. Você teve a disciplina de Pedologia durante a sua formação?

\begin{tabular}{c|c|c}
\hline Campus & Sim & Não \\
\hline Ourinhos & 78 & 2 \\
\hline Presidente Prudente & 16 & 64 \\
\hline Rio Claro & 53 & 27 \\
\hline
\end{tabular}

Fonte: Elaborado pelos autores.

Observa-se que $97 \%$ dos entrevistados de egresso no campus de Ourinhos cursaram a disciplina de Pedologia em algum ano de sua graduação. Esse fato se deve à disciplina ser obrigatória tanto para a licenciatura quanto ao bacharelado, desde o início do campus de Ourinhos, em 2003. A não totalidade pelo Campus de Ourinhos é justificada pela presença de alunos advindos de outras faculdades ou universidades. Já com relação aos entrevistados do campus de Presidente Prudente, $80 \%$ não cursaram essa disciplina em sua graduação, pelo fato da disciplina ser optativa. Em Rio Claro, 66\% dos egressos cursaram a disciplina, já que é obrigatória para grande parte das ênfases da Geografia, bem como bacharelado sem ênfase, com ênfase em Análise Ambiental e Geoprocessamento e Planejamento Territorial.

2. Você utiliza em seu trabalho alguma discussão relacionada à formação e conservação dos solos?

\begin{tabular}{c|c|c}
\hline Campus & Sim & Não \\
\hline Ourinhos & 29 & 51 \\
\hline Presidente Prudente & 9 & 71 \\
\hline Rio Claro & 15 & 65 \\
\hline
\end{tabular}

Fonte: Elaborado pelos autores.

O objetivo era identificar o fluxo de licenciados e/ou bacharéis que trabalham/atuam no mercado de trabalho e utilizam alguma discussão relacionada à formação e conservação dos solos, seja na elaboração de EIA/Rima's, consultoria ambiental, secretaria de prefeituras, em sala de aula, em instituições como Embrapa, IAC etc. E os resultados apontaram que a minoria dos entrevistados utiliza em algum contexto práticas estudadas nas disciplinas de Pedologia.

3. Você participou de algum projeto de extensão universitária onde questões relacionadas à educação ambiental eram discutidas? 


\begin{tabular}{c|c|c}
\hline Campus & Sim & Não \\
\hline Ourinhos & 51 & 29 \\
\hline Presidente Prudente & 23 & 57 \\
\hline Rio Claro & 36 & 44 \\
\hline
\end{tabular}

Fonte: Elaborado pelos autores.

A proposta era observar a atuação dos projetos de extensão universitária voltados à educação ambiental, como o Trilhando pelos Solos, Coloide e Núcleo de Pesquisas sobre Desastres (Nuped), por exemplo.

4. Seu Trabalho de Conclusão de Curso (TCC) abrangeu discussões relacionadas à educação ambiental e/ou a educação em solos?

\begin{tabular}{c|c|c}
\hline Campus & Sim & Não \\
\hline Ourinhos & 45 & 35 \\
\hline Presidente Prudente & 22 & 58 \\
\hline Rio Claro & 36 & 44 \\
\hline
\end{tabular}

Fonte: Elaborado pelos autores.

Nessa questão, os principais temas de TCC abordados pelos egressos de Ourinhos foram combate à erosão do solo, materiais didáticos visando à educação ambiental e erosão hídrica e seus impactos no solo. Em Presidente Prudente, onde 58 egressos não abordaram questões relacionadas à educação ambiental e/ou educação em solos, destacaram-se os temas análise do território, Climatologia e geografia urbana. Dentre os assuntos mais abordados pela temática da educação ambiental e/ou educação em solos, em Rio Claro, foram formação e conservação do solo, práticas educacionais para o estudo de solos no Ensino Fundamental e Médio e fotopedologia.

\section{Considerações finais}

A baixa conformidade entre a oferta da disciplina de Pedologia nos cursos de Geografia nos três campi se deve à divergência enquanto obrigatória ou optativa na grade curricular. Há baixa consonância no conteúdo programático e nos objetivos da matéria.

O caráter obrigatório da disciplina teve como consequência o aumento de pesquisas voltadas à educação ambiental e/ou educação em solos, tendo o campus de Ourinhos como destaque nessa abordagem.

As participações em iniciações cientificas voltadas para a educação ambiental possibilitaram a elaboração de trabalhos de conclusão de curso na área, visto os números semelhantes para ambas as questões.

A educação ambiental configura-se como um objeto de estudo importante para a ciência geográfica, observando na Pedologia uma aplicabilidade significativa na busca de formar profissionais preconizadores da educação ambiental em seu sentido mais amplo. 


\section{Referências}

BIONDI, D., FALKOWSKI, V. Avaliação de uma atividade de educação ambiental com o tema "solo". Rev. eletrônica Mestr. Educ. Ambiental. Rio Grande: v. 22, n. 1, p. 202-215, 2009.

CASTELLAR, S.M.V. O ensino de geografia e a formação docente. In: CARVALHO, A.M.P. (Coord.). Formação continuada de professores. São Paulo: Pioneira/Thomson, 2003.

CHERVEL, A. A história das disciplinas escolares: reflexões sobre um campo de pesquisa. Teoria \& Educação, Porto Alegre: v. 2, p. 177-229, 1990.

COSTA, R. C. O Ensino de solos na Geografia da Educação Básica no Estado de São Paulo e algumas experiências no município de Ourinhos/SP. 2012. 137f. Trabalho de Conclusão de Curso (Graduação em Geografia) - Universidade Estadual Paulista, Ourinhos, 2012.

CUNHA, J. E. et al. Práticas pedagógicas para ensino sobre solos: aplicação à preservação ambiental. Terrae Didatica, Campinas: v. 9, n. 2, p. 74-81, 2013.

GOODSON, I. Tornando-se uma disciplina acadêmica: padrões de explicação e evolução. Teoria \& Educação. Porto Alegre: v. 2, p. 230-254, 1990.

JENNY, H. Factors of soil formation: a system of quantitative pedology. McGraw-Hill, New York: 281 p., 1941.

MCBRATNEY, A. B. B. et al. On digital soil mapping. Geoderma, Amsterdan: v. 117, p. 3-52, 2003.

MONIZ, A. C. A história da Pedologia no Brasil. Boletim Informativo da Sociedade Brasileira de Ciência do Solo, Campinas, v. 22, n. 1, p.13-31, 1997.

MUGGLER, C. C., SOBRINHO, F. A. P., MACHADO, V. A. Educação em Solos: princípios, teoria e métodos. Rev. Bras. de Ciên. do Solo, Ribeirão Preto: p. 733-740, 2006.

OLIVEIRA, C. R. P., CUNHA, J. E. Educação ambiental: abordagem no ensino superior de Geografia. Geografia Ensino \& Pesquisa, v. 16, n. 1, janjun. 2012.

PACHECO, J. A. Formação de professores: documento de discussão. Rev. Educar Minho Comunicação SPCE/95, Universidade do Minho, Portugal, 2003.

PEREIRA, D.A.C. Origens e consolidação da tradição didática na Geografia escolar brasileira. 1989. 241f. Dissertação (Mestrado em Geografia). Universidade de São Paulo, 1989.

QUEIROZ NETO, J. P. Pedologia: conceito, método e aplicações. Rev. Dep. De Geografia. São Paulo: v. 3, p. 95-102, 1986.

RAMOS, J., MARINHO, N., FRANCO, G. B. Uma análise acerca dos conteúdos de pedologia nos livros didáticos de geografia do ensino médio. In: SIMPÓSIO BRASILEIRO DE GEOGRAFIA FÍSICA APLICADA, 7, 2017, Campinas. Anais do XVII Simpósio Brasileiro de Geografia Física Aplicada. Campinas: Universidade Estadual de Campinas, v. 1, 2017. p. 3701-3704.

ROCHA, G. O. R. A trajetória da disciplina Geografia no currículo escolar brasileiro (1837 - 1942). 297 p. Dissertação (Mestrado em Educação) -Pontifícia Universidade Católica de São Paulo, São Paulo, 1996. 
SANTOS, F. A. A escola nova e as prescrições destinadas ao ensino da disciplina de Geografia da escola primária em São Paulo no início do século XX. 195p. Dissertação (Mestrado em Educação: História, Política e Sociedade) -Pontifícia Universidade Católica de São Paulo, São Paulo, 2005.

SANTOS O.; BEVENIDES A. A. Educação em solo: investigação em uma escola do campo. In: CONGRESSO NACIONAL DE EDUCAÇÃO, 12, 2015. Anais do Congresso Nacional de Educação. Curitiba: Pontifícia Universidade Católica do Paraná, 2015. p. 21116-21124.

SILVA, A. C., RIBEIRO, A. L. S. A disciplina pedologia ministrada nos cursos de geografia em diversas cidades maranhenses por meio do Procad. Geografia, Londrina: v. 13, n. 1, p. 143-150, jan-jun. 2004.

SOUZA JUNIOR, M., GALVÃO, A. M. O. História das disciplinas escolares e história da educação: algumas reflexões. Educação e Pesquisa, São Paulo, v. 31, n. 3, p. 391-408, set-dez. 2005.

United States Department of Agriculture (USDA). Soil taxonomy: a basic system of soil classification for making and interpreting soil surveys. 2. ed. Washington: Natural Resources Conservation Service, 1999. v. 1, 834 p.

UNIVERSIDADE ESTADUAL PAULISTA. Projeto Pedagógico do curso de Geografia da FCTUNESP. Departamento de Geografia da Faculdade de Ciências e Tecnologia de Presidente Prudente. Presidente Prudente, 2004.

. Projeto Pedagógico do curso de Geografia da FCT-UNESP. Departamento de Geografia da Faculdade de Ciências e Tecnologia de Presidente Prudente. Presidente Prudente, 2014.

. Grade Curricular de Geografia - Integral (Currículo Novo). Instituto de Geociências e Ciências Exatas (Seção Técnica de Graduação). Rio Claro, 2014.

. Estrutura Curricular de Geografia. Seção Técnica de Apoio Acadêmico. Campus de Ourinhos. Ourinhos, 2015. 